\title{
Biotechnological peculiarities of microalgae chlorella production and use in poultry
}

\author{
Nadezhda Machneva ${ }^{1}$, Anna Gneush ${ }^{1, *}$ and Kirill Ivanov². \\ ${ }^{1}$ Federal State Budgetary Educational Institution of Higher Education "Kuban State Agrarian \\ University named after I.T. Trubilin”, 350044 Kalinina str., 13, Krasnodar, Russia \\ ${ }^{2}$ Niigata University, 9502081, Ikarashi 2-no-cho, 8050, Nishi-ku, Niigata, Niigata, Japan
}

\begin{abstract}
The current paper presents data on the features of biotechnological cultivation of chlorella microalgae strain IFR C-111 on different nutrient media. Evaluation of the influence of the illumination period on the rate of biomass growth on the selected nutrient medium has also been presented. There are materials of microalgae suspension influence the effect on the biological resource's potential of quails.
\end{abstract}

Disclosure of the bioresource potential is an important goal of poultry production, which will only be realized with the high-quality diets using. The development and production of high-quality diets depend on the quality of the raw materials and the functionality of the additives are used. One of these additives is the microalgae chlorella [1]. The interest in this one can be explained by its biochemical characteristics, which make it attractive not only in poultry farming but also in animal husbandry, since it replenishes the protein deficit with all essential amino acids and the vitamin spectrum, including fat-soluble ones, as well as microand macro elements in a bioavailable form. Microalgae can synthesize a natural antibiotic called "chlorellin" which is active against Gram-positive and Gram-negative microorganisms $[2,3]$. The geographical features of the Russian Federation and other countries of the world are not always able to provide the available livestock with the necessary amount of fodder units at the expense of regional fodder raw materials. The search for alternative sources of biotechnological produced fodder raw materials that don't depend on natural and climatic conditions is an important and promising trend in the development of agriculture.

Analysis of existing technologies of microalgae suspension cultivation and production is aimed at increasing the number of cells per unit volume, as well as reducing the cultivation time $[4,5]$. The authors of the developments, solving the specified problem, use such methods as modernization of technological equipment, optimization of nutrient medium, as well as biophysical methods of treatment aimed at increasing the yield of the target product and reducing the cost of production technology of microalgae. The chemical composition of the chlorella suspension depends on the composition of the nutrient medium: a medium rich in nitrogen allows the accumulation of protein, in another way, a lack of nitrogen leads to an accumulation of lipids and carbohydrates [2, 3]. Optimization of cultivation conditions of microalgae will produce a suspension with a biochemical composition satisfying the needs of poultry in nutrients. The work described in this article aimed to study the features of

*Corresponding author: gneush.anna@yandex.ru 
biotechnology of chlorella microalgae production and its use in poultry production, allowing to increase the productivity and safety of poultry, improve the quality and biological safety of commercial products by reducing the number of synthetic additives.

On the basis of the designated purpose, the following tasks were performed: the optimal nutrient medium analysis; adjustment of technological regimes of microalgae cultivation and methods of obtaining a highly concentrated suspension; the study of the obtained fodder affect on the bioresource potential of poultry. The object of the study was strain IFR C-111 cultivated on a nutrient medium optimized by N. I. Bogdanov [4, 5]. Studies were carried out at the Department of Biotechnology, Biochemistry, and Biophysics (obtaining and assessing the quality of the microalgae suspension), as well as at the Research and Testing Center of Toxicopharmacological Research and Development of Veterinary Drugs, Feed Supplements and Disinfectants (RC Vetfarmbiocenter), which is a structural unit of the FSBEI of HE "Kuban State Agrarian University named after I. T. Trubilin" (evaluation of acute toxicity, and the impact of the resulting preparation on the bioresource potential of the Texas quail breed).

In order to obtain the production volume of microalgae preparation in laboratory conditions, we carried out research on a comparative analysis of the most perspective nutrient medium. We used Bogdanov N.I. nutrient medium and standard laboratory nutrient medium used for cultivation of chlorella microalgae, called “Tamiya”. Nutrient media were compared in terms of microalgae biomass growing rate and production cost. Microalgae were cultivated for five days in a 100 -liter glass cylindrical laboratory bioreactor at $28-30{ }^{\circ} \mathrm{C}$. Illumination was performed for 18 hours a day with white fluorescent lamps [6, 7]. During cultivation, the nutrient medium was bubbling with non-sterile air with the addition of carbon dioxide during the daytime. The two most perspective nutrient media, Bogdanov N. I. medium, and "Tamiya" medium were identified in the course of earlier laboratory studies. The rate of biomass growth during the growing period was monitored. It was found that the use of the "Tamiya" medium in production is impossible not only because of its high cost but also because of the difficulty of using the chlorella suspension grown on this nutrient medium due to the toxicity of its constituent elements for livestock $[6,7]$. We decide to use this nutrient medium as a control medium.

The average values of the concentration of Chlorella vulgaris cells of IFR № C-111 obtained as a result of three repetitions on Tamiya and N. I. Bogdanov media are shown in Table 1.

At the beginning of the cultivation period (the first day), the concentration of Chlorella on N. I. Bogdanov's medium was slightly higher than the control. After three days of cultivation, the cell concentration on the experimental nutrient medium exceeded the control by $43,3 \%$. Then, the experiment was continued up to five days and the concentration of Chlorella vulgaris IFR № C-111 on Tamiya medium increased 3.5-fold, and on N. I. Bogdanov medium, 5.3-fold.

Table 1. Chlorella vulgaris IFR № C-111 cells growth dynamics on tested nutrient media

\begin{tabular}{|c|c|c|}
\hline \multirow{2}{*}{ Cultivation time, days } & \multicolumn{2}{|c|}{ Cell's concentration in nutrient medium (10cells/ml) } \\
\cline { 2 - 3 } & $100 \%$ Tamiya medium (control) & $100 \%$ N. I. Bogdanov medium \\
\hline 1 & $31,2 \pm 1,4$ & $32,3 \pm 1,4$ \\
\hline 3 & $72,3 \pm 2,3$ & $103,6 \pm 3,1$ \\
\hline 5 & $110,4 \pm 3,6$ & $172,6 \pm 5,8$ \\
\hline
\end{tabular}

Based on the data shown in Table 1, it was found that the most promising nutrient medium for obtaining biomass of microalgae chlorella is Bogdanov N. I. nutrient medium, since the biomass of cells of the experimental group exceeded the data obtained on the control nutrient medium by $56.3 \%$, as well as there is no toxic effect of nutrient medium components.

To adjust the technological regimes of cultivation on the selected nutrient medium, the effect of periodic lighting during a daylight regime of $16 \mathrm{~h}, 18 \mathrm{~h}$, and $20 \mathrm{~h}$ continuous lighting was studied. The results of cell-growth dynamics are presented in Table 2. 
Table 2. Growth dynamics of Chlorella vulgaris cells IFR № C-111 under different light conditions

\begin{tabular}{|c|c|c|c|}
\multirow{2}{*}{$\begin{array}{c}\text { Cultivation time, } \\
\text { days }\end{array}$} & \multicolumn{3}{|c|}{ Cell's concentration in nutrient medium $\left(10^{4} \mathrm{cells} / \mathrm{ml}\right)$ depended on light, $\mathrm{h}$} \\
\cline { 2 - 4 } & $16 \mathrm{~h}$ & $18 \mathrm{~h}$ & $20 \mathrm{~h}$ \\
\hline $1^{\text {st }}$ day & $33,3 \pm 1,2$ & $35,4 \pm 1,3$ & $35,6 \pm 1,2$ \\
\hline $5^{\text {th }}$ day & $164,6 \pm 3,4$ & $178,4 \pm 3,2$ & $180,1 \pm 4,1$ \\
\hline
\end{tabular}

The results presented in Table 2 allow us to conclude that the most optimal light regime of cultivation is a time interval with the illumination of 18 hours per day since in this regime the maximum increase in cell biomass was observed, exceeding by $8.4 \%$ the cell growth at illumination duration of 16 hours. At the same time, the increase in biomass growth at an illumination of the suspension of 20 hours exceeded by $0.9 \%$ the group with the illumination of 18 hours. But this increase in cell biomass is not economically feasible because of the increasing cost of electricity used when increasing the duration of illumination.

The next stage of the research was to study the effect of the obtained fodder based on chlorella microalgae on the bioresource potential of farm birds. To implement the task, three groups of quails at the age of three days were formed, since from the first to the third day of life is the equating period and is aimed at culling the studied stock. The first group of quail received a standard (control) diet. Groups two and three received, together with the basic diet, free-range chlorella microalgae suspension as a drinking solution. In the second experimental group, the concentration of cells in the drinking solution was $1.8 \times 10^{6} \mathrm{cells} / \mathrm{ml}$. The third experimental group under the same conditions received a suspension of chlorella microalgae with a concentration of $1.8 \times 10^{4}$ cells $/ \mathrm{ml}$. The receiving a dose of additive was obtained once every five days.

Evaluation of the bioresource potential of the experimental poultry stock was carried out according to the main zoo-technical and physiological indicators. Table 3 shows zootechnical indicators for the entire period of poultry breeding. During the experiment, three groups of quails were formed, with 60 birds in each group receiving standard mixed fodder as the basic one. The second and third experimental groups received a suspension of microalgae in appropriate concentrations as a drinking additive.

Table 3. Survival rate and dynamics of live weight of quail, $n=60$

\begin{tabular}{|c|c|c|c|}
\hline \multirow{2}{*}{ Indicator } & \multicolumn{3}{|c|}{ Group } \\
\cline { 2 - 4 } & I (control) & II experimental & III experimental \\
\hline $\begin{array}{c}\text { Survival rate during } \\
\text { breeding period, } \%\end{array}$ & 93,3 & 95,0 & 93,3 \\
\hline \multicolumn{4}{|c|}{ Dynamics of light weight, $g$} \\
\hline $3^{\text {rd }}$ day & $23,12 \pm 0,13$ & $23,15 \pm 0,14$ & $23,21 \pm 0,12$ \\
\hline $7^{\text {th }}$ day & $50,27 \pm 0,63$ & $50,12 \pm 0,61$ & $49,89 \pm 0,58$ \\
\hline $14^{\text {th }}$ day & $103,16 \pm 2,19$ & $105,65 \pm 2,19$ & $103,47 \pm 2,21$ \\
\hline $21^{\text {st }}$ day & $172,12 \pm 3,17$ & $175,89 \pm 2,96$ & $172,74 \pm 2,83$ \\
\hline $28^{\text {th }}$ day & $200,24 \pm 4,24$ & $209,15 \pm 4,31$ & $202,38 \pm 4,46$ \\
\hline $35^{\text {th }}$ day & $247,97 \pm 5,08$ & $260,15 \pm 5,15$ & $250,16 \pm 5,12$ \\
\hline $42^{\text {nd }}$ day & $272,17 \pm 5,60$ & $287,48 \pm 5,74$ & $273,62 \pm 5,58$ \\
\hline \multicolumn{4}{|c|}{ Growth of quail's live mass during the breeding period (0-42 days) } \\
\hline One bird on average, g. & 249,05 & 264,33 & 250,41 \\
\hline \multicolumn{4}{|c|}{ Daily average, g. }
\end{tabular}

Analysis of the data in Table 3 shows that the greatest increase in live weight of quails was observed in the second experimental group and exceeded the control by 5,6\%, while the third experimental group exceeded the control insignificantly (by 0,5\%). Accordingly, the highest average daily gain was observed in the second experimental group and amounted to $6,77 \mathrm{~g}$.

After 42 days of breeding, the quails were slaughtered to determine their meat productivity.

The table 4 shows that the highest value of gutted quail carcass weight, concerning the control, was observed in the second experimental group (5,9\%). In the same group, there was 
an increase in the total volume of edible muscles, exceeding the control by $11 \%$; in the third group, this indicator exceeded the control by $2,3 \%$.

Table 4. Meat productivity of quail, $\mathrm{n}=10$

\begin{tabular}{|c|c|c|c|}
\hline \multirow{2}{*}{ Indicator } & \multicolumn{3}{|c|}{ Group } \\
\cline { 2 - 4 } & I (control) & II experimental & III experimental \\
\hline $\begin{array}{c}\text { Poultry life weight } \\
\text { before slaughter, g }\end{array}$ & $271,83 \pm 5,36$ & $285,49 \pm 5,48$ & $271,98 \pm 5,47$ \\
\hline $\begin{array}{c}\text { Carcass weight after } \\
\text { exsanguination, g }\end{array}$ & $264,42 \pm 4,89$ & $276,37 \pm 4,85$ & $265,04 \pm 4,93$ \\
\hline $\begin{array}{c}\text { Weight of not gutted } \\
\text { carcass, g }\end{array}$ & $246,3 \pm 4,25$ & $256,8 \pm 4,32$ & $247,1 \pm 4,82$ \\
\hline $\begin{array}{c}\text { Weight of gutted } \\
\text { carcass, g }\end{array}$ & $203,1 \pm 4,15$ & $215,1 \pm 4,12$ & $204,6 \pm 4,09$ \\
\hline $\begin{array}{c}\text { Weight of thigh } \\
\text { muscles, g }\end{array}$ & $21,4 \pm 1,08$ & $24,1 \pm 0,89$ & $21,8 \pm 1,1$ \\
\hline Tibia muscles, g & $10,43 \pm 0,41$ & $12,1 \pm 0,37$ & $11,09 \pm 0,35$ \\
\hline Breast muscles, g & $58,7 \pm 2,16$ & $63,1 \pm 2,01$ & $59,8 \pm 2,15$ \\
\hline $\begin{array}{c}\text { Weight of other } \\
\text { muscles, g }\end{array}$ & $10,2 \pm 0,36$ & $12,6 \pm 0,37$ & $10,4 \pm 0,39$ \\
\hline Total edible muscles, g & $100,73 \pm 2,52$ & $111,9 \pm 2,48$ & 103,09 \\
\hline
\end{tabular}

Evaluation of morphological blood parameters showed their compliance with the physiological norms of poultry and is presented in Table 5.

Table 5. Morphological indicators of quail blood, $n=10$

\begin{tabular}{|c|c|c|c|}
\hline \multirow{2}{*}{ Indicator } & \multicolumn{3}{|c|}{ Group } \\
\cline { 2 - 4 } & I (control) & II experimental & III experimental \\
\hline Erythrocytes, $10^{12} / 1$ & $3,36 \pm 0,13$ & $3,42 \pm 0,17$ & $3,39 \pm 0,19$ \\
\hline Thrombocytes, $10^{9} / 1$ & $124,26 \pm 4,05$ & $126,01 \pm 4,23$ & $125,62 \pm 4,12$ \\
\hline Leukocytes, $10^{9} / 1$ & $24,36 \pm 0,36$ & $23,32 \pm 0,32$ & $23,89 \pm 0,33$ \\
\hline Hemoglobin, $\Gamma / 1$ & $130,02 \pm 3,78$ & $134,94 \pm 3,82$ & $132,39 \pm 3,93$ \\
\hline
\end{tabular}

It should be noted that in the experimental groups all the studied parameters slightly exceeded the control. Thus, the content of erythrocytes was higher than control in the second and third experimental groups by $1,8 \%$ and $0,9 \%$, respectively. The highest blood hemoglobin content of the second and third experimental groups exceeded the control by $3,8 \%$ and $1,8 \%$, respectively.

Having analyzed all the experimental data, we can talk about the positive effect of chlorella microalgae suspension on the bioresource potential of experimental birds. It should be noted that the best results were obtained in the second experimental group receiving the microalgae suspension with the concentration of cells in the watering solution of $1.8 \times 10^{6}$ cells/ml.

Based on the carried-out investigations, the data on the positive dynamics of growth of the chlorella suspension on N. I. Bogdanov's medium were obtained, exceeding the indicators of the control medium by 56,3\%, as well as the increase in the rate of cell biomass growth during the light period of 18 hours.

The inclusion of microalgae suspension into the diet of quails had a positive effect on the main zoo-technical and morphological parameters of the quails.

\section{References}

1 N. I. Bogdanov, Use of chlorella in the diet of agricultural animals, reports of the Russian Acad. of Agricult. Sciences (reports of the RAoAS) 1, 34-36, (2004) 
2 S. Cao, D. Zhang, F. Teng, R. Liao, Z. Cai, Y. Tao, H. Hu, Inhibitory effects of ultralowdose sodium hypochlorite on Microcystis aeruginosa and Chlorella vulgaris: differences in sensitivity and physiology, Science of The Total Envi., 774, 145638, (2021).

3 K. Y. Teh, S.H. Loh, A. Aziz, K. Takahashi, A.W.M. Effendy, T.S. Cha, Lipid accumulation patterns and role of different fatty acid types towards mitigating salinity fluctuations in Chlorella vulgaris, Scientific rep., 11 (1), 1-12, (2021).

4 M.V. Kunitsin, N. I. Bogdanov, Rus. Fed. Patent № 2176667, Method for the cultivation of microalgae, based on strain "Chlorella vulgaris IFR № C-111", 34, (2001)

5 M.V. Kunitsin, N. I. Bogdanov, Rus. Fed. Patent № 2268923, Plant for microalgae cultivation, 3, (2004)

6 N. L. Machneva, A. G. Koschaev, G. A. Plutakhin, Selection of a nutrient medium for the cultivation of microalgae chlorella and assessment of its effectiveness in quail diets, Adv. in Agric. and Biol. Sciences 2, 31-40, (2017).

7 G. A. Plutakhin, N. L. Machneva, N.N.Trokhimchuk, Intensification of chlorella cultivation using iron nanoparticles, Polythem. network electr. scientific journal of the KSAU, 126, 760-774, (2017) 